\title{
RAINFALL QUALITY AT SELECTED \\ SITES IN SAUDI ARABIA
}

\author{
by Alonzo H. Handy \\ and Roger A. Tucker
}

MINISTRY OF AGRICULTURE AND WATER

WATER RESOURCES DEVELOPMENT DEPARTMENT

WATER RESEARCH AND STUDY DIVISION

PUBLICATION NO. 2 , VOL. 8

OPEN FILE REPORT 84-604 
CONTENTS

Page

Introduction

Physiographic Description of Saudi Arabia 3

Summary of Climatic Conditions $\quad 6$

Purpose of Study $\quad 8$

Description of Study

Location of Sites 9

Meteorological Equipment 11

Water Quality Equipment $\quad 12$

Results of Study

Rainfall Quality Samples 16

Dry Fallout Samples $\quad 22$

$\begin{array}{ll}\text { Summary and Conclusions } & 26\end{array}$

$\begin{array}{ll}\text { References } & 27\end{array}$

Illustrations

Figure 1. Map Showing Mean Annual Precipitation

in Saudi Arabia 2

2. Sketch of Wet-Dry Precipitation Collector 15 


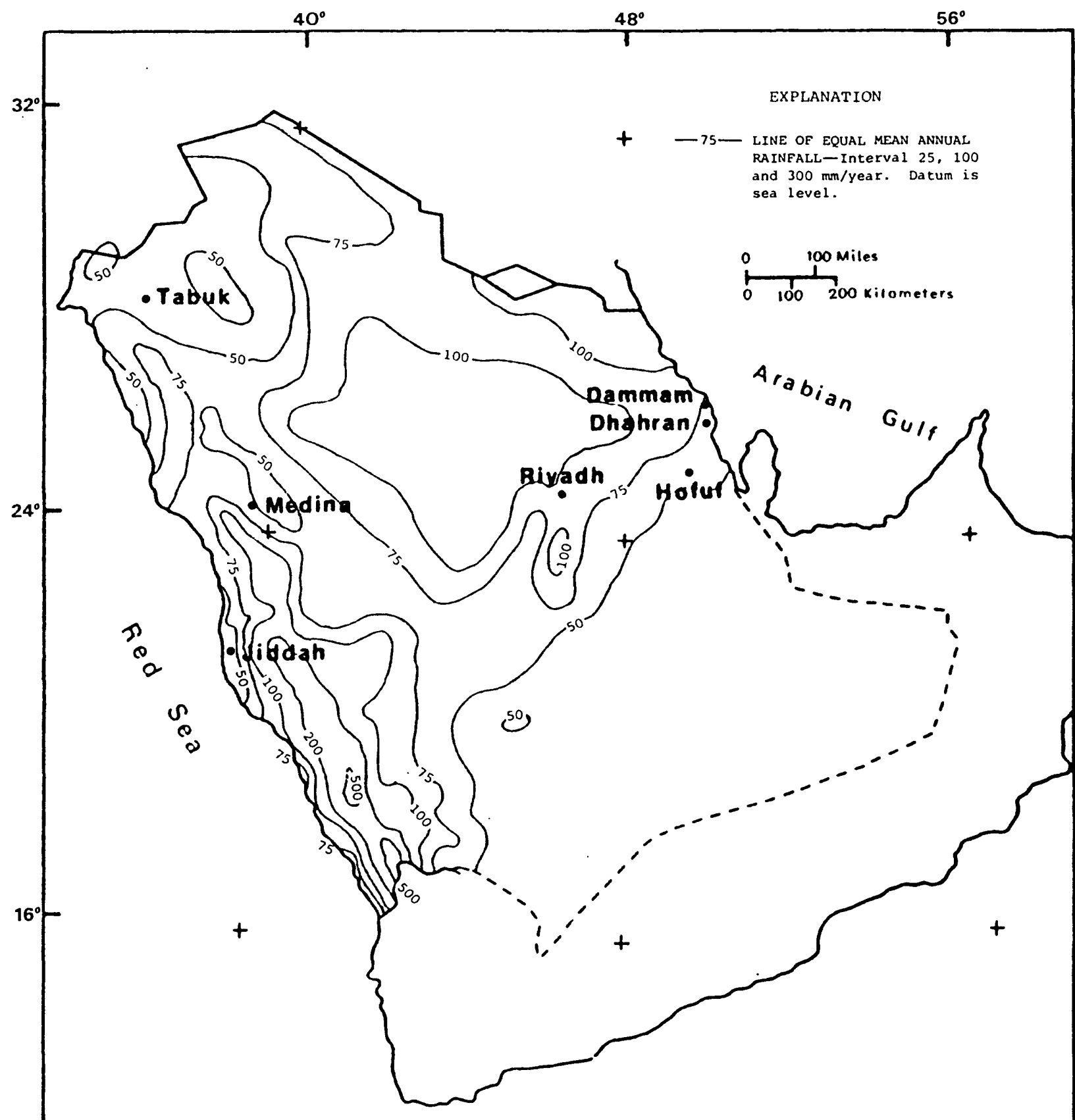

(Shampine and others, 1979)

Figure 1. -- Mean Annual Precipitation in Saudi Arabia 


\section{Precipitation Quality at Selected Sites \\ in Saudi Arabia}

A. H. Handy and R. A. Tucker

\section{INTRODUCTION}

Physiographic Description of Saudi Arabia

The Kingdom of Saudi Arabia is mostly a tropical and subtropical desert consisting of 2,107,429 square kilometers which is approximately four-fifths of the entire Arabian Peninsula. Saudi Arabia is bordered on the north by Jordan, on the north-east by Kuwait, the Arabian Gulf and the United Arab Emirates, on the east by the Sultanate of Oman, on the South by the People's Democratic Republic of South Yemen and the Arab Republic of Yemen and on the west by the Red Sea and Gulf of Aqabah.

Although Saudi Arabia is bordered on two sides by water, aridity is its dominant feature. The Red Sea with a length of over 1,800 kilometers extends NW-SE separating Saudi Arabia from Africa. The width of the sea varies from 175 kilometers in the north to a maximum of 350 kilometers near Jizan. The second body of water is the Arabian Gulf which borders the Eastern Provinces of Saudi Arabia. This shallow epicontinental sea is very broad and had a maximum depth of about 110 meters. Its shore line contains many salt flats or sabkhahs. These sabkhahs generally have thin surface crusts of salt due to the high evaporation. 
Wadis crisscross all of Saudi Arabia, however, there are no perennial streams by true definition. Wadi Lith near Al Lith, Wadi Hali near Muhayil, and Wadi Khulab near Suq $A l$ Ahab are fed by springs and are the closest to perennial streams in the Kingdom. Infrequent heavy rainfalls in Saudi Arabia result in flowing wadis and local floods but the water from most rainfalls is usually absorbed by the alluvium in the dry wadi before it travels more than a few kilometers. Numerous dams for flood control and groundwater recharge are located throughout the Kingdom but storage of surface water is limited to the reservoirs behind the large dams at Abha and Jizan, and the natural Layla Lakes near Layla. Natural outflows of water in the form of springs occur in the Al Hasa area near Hufuf.

About one third of the Arabian Peninsula is covered by eolian sand which was either eroded or deposited by the wind. In southern Arabia the sand region of Ar Rub'a1-Khali or Empty Quarter extends for 1,200 kilometers with a maximum width of 650 kilometers and a total area of 600,000 square kilometers. This is the largest continuous body of sand in the world. Long cliffs or escarpments that separate two comparatively level or more gently sloping surfaces are a common feature in Saudi Arabia. The largest is the Tuwayq escarpment located west of Riyadh. It is 800 kilometers long with an average elevation of 840 meters above sea level with a maximum elevation of about 1,500 meters. 
Although there are several plateaus in Saudi Arabia the most pronounced features are the mountains of the Hejaz and Asir in the west and southwest. These mountains which rise to a height of approximately 3,300 meters near Abha, are often referred to as scarp mountains. Mountains extend from the Gulf of Aqabah in the north through Saudi Arabia to its southern tip with a varying width of 40 to 140 kilometers. The higher and more rugged mountains are in the southwest and they decrease in height and ruggedness northward. The most pronounced decrease is from Taif and Makkah northward. 


\section{Summary of Climatic Conditions}

Although bordered by water on two sides, aridity is the dominant climatic feature of Saudi Arabia. Most of the country is a tropical or subtropical desert. The climate of Saudi Arabia is influenced by air masses that move into the country mainly from the west and north. The Asir mountains block climatic influences from tropical zones to the south. Most of the country has long, hot, and dry summers and short, cool winters. Summer temperatures frequently exceed $48^{\circ}$ Celsius throughout the inland areas of Saudi Arabia. In general, the most frequent direction of prevailing wind is from the west to northwest in the Kingdom. Frequent strong northerly winds called "shamals" occur about mid-summer. Wind gusts of up to 100 Kilometers per hour have been recorded in these shamals. These winds decrease by the end of July and the least amount of wind occurs during August. During the winter months of December through February strong variable winds frequently occur with storms. (Williams, 1979) However, as the spring months of March through May approach these persistent strong winds decrease in frequency. Winds in the mountainous areas persist with wind speeds up to 70 percent greater than the winds in the lowlands to the east. High winds of 100 kilometers per hour or greater have been recorded from the southeast at Jizan, from the east at Sulayyil, and from the northwest at Madinah. (E1 Khatib, 1980). 
Cloudless days and nights are found throughout the Kingdom with the exception of the Asir area where clouds occur quite frequently year around. Seasonal clouds do occur with the influx of synoptic weather systems. The cloudless days allow for maximum sunshine hours and a mean monthly maximum solar radiation of about 600 langleys per day between the months of June and $\mathrm{Ju} 1 \mathrm{y}$.

Rainfall which occurs mainly from October to April in most of the Kingdom is scant, irregular, and unreliable. The mean annual rainfall is 100 millimeters or less except in the Asir region where amounts in excess of 500 millimeters are not uncommon. (See figure 1) Summer rainfall is confined to the Asir. Spring rainfall is recorded mainly in the central and southern regions, while winter rainfall occurs in significant amounts in the northern, western, and eastern regions of the Kingdom. Rainfall of 100 to 200 millimeters occur in areas extending from north of Riyadh to the vicinity of Hail. The annual rainfall in the central interior of the Kingdom is between 50 to 100 millimeters. The Jeddah area receives an annual rainfall of 50 to 100 millimeters occurring mainly during the winter season while the Taif area receives rainfall throughout the year with an annual mean of 100 to 200 millimeters. (Al-Qurashi, 1981) In general, rainfall is sporadic and sometimes localized heavy rains occur during short periods causing flash floods. 


\section{Purpose of Study}

The rainfall - water quality study at selected sites in Saudi Arabia was initiated in response to the Director General's, WRDD request to determine the chemical composition of the rainfall in Saudi Arabia. The initial sites at Riyadh, Hufuf, Abha, and Tabuk were selected to start the study. Since rainfall is sporadic and unpredictable long periods of time pass before any samples are collected. To date there has been a limited number of samples collected. Therefore, this report based on these few samples, is preliminary in nature. The report also serves as a notification that such a study has been undertaken by the Ministry of Agriculture and Water. 
DESCRIPTION OF STUDY

Location of Sites

In April of 1983, wet-dry precipitation collectors were installed in Riyadh, Hufuf, and Abha, Saudi Arabia. In October of 1983, a fourth station was added in Tabuk. These sites are the first sites selected as part of an expanding network of stations to define the chemical characteristics of rainfall in Saudi Arabia. (See Figure 1.)

Riyadh was chosen because it is an expanding urban area in a large city of over a million people. The meteorological site is located at the Ministry of Agriculture and Water's Regional Agricultural Research Center near the center of the city, and the actual sampling site is a few miles away in a growing urban area. Both heavy and light industrial areas are found near Riyadh with oil refineries, cement plants, plastics factories, car assembly plants, and brick factories among the local industries. In addition, road and large building construction, airport construction, and extensive private home construction are in progress. Large numbers of diesel and gasoline trucks of all sizes and private automobiles are found on the new roads and streets. Also, Riyadh is located in the central desert area of Saudi Arabia. 
Hufuf is a moderately sized city of near 250,000 inhabitants located in a traditionally agricultural area near the east coast of the Arabian Gulf. However, Hufuf is also growing rapidly and construction of roads, buildings, and light industries are evident. The sampling site, representing the coastal areas of the Eastern Province, is located in an agricultural area. The sampler was installed at the meteorological measuring site at the Hufuf Research Station. The Ministry of Agriculture and Water regional office is located there. Large numbers of date palms, pomegranate bushes, vegetable farms, and wheat farms are located near the Hufuf Research Station. Also, the road to Dammam passes nearby with large number of diesel and gasoline vehicles using the road.

The meteorological site at Abha was chosen to represent the mountainous area of the Asir. Abha is located in the mountains but is also a city of about 75,000 people. The sampler was placed at the Ministry of Agriculture and Water office near Abha Reservoir. This area is residential and light industrial. Also, it is near a major highway around the town. Although construction is heavy in Abha, the area near the sampler has been built up previously and construction is not currently heavy.

Tabuk was chosen to represent the desert areas in the northwest of Saudi Arabia. Tabuk is a rapidly developing city of about 100,000 inhabitants located near an expanding agricultural area. Also, the city itself contains some light industry, much road and building construction and many automobiles. Tabuk has some influence from the Red Sea but not as much as cities further south like Yanbu and Jeddah. 


\section{Meteorological Equipment}

The rainfall-water quality samplers were installed at the Ministry of Agriculture and Water's meteorological data collection stations at Hufuf, Abha, and Tabuk. At Riyadh the sampler is located at a private villa with adequate exposure. There also is a meteorological station in Riyadh. The Ministry of Agriculture and Water has approximately 550 rain gauge sites and 50 meteorological sites located throughout the Kingdom. The parameters collected at the meteorological stations are air temperature, relative humidity, rainfall, pan evaporation, sunshine duration, solar radiation, wind speed, wind direction, and soil temperatures. Daily values of these parameters are collected and monthly summaries are reported.

Where more than one rain gauge is located at a meteorological station, the priority of gauge readings is (1) recording rain gauge, (2) standard " 8 " rain gauge, and (3) totalizer rain gauge. The rainfall data are recorded to the nearest 0.1 millimeter. Amount and intensity of rainfall for each storm was collected to correspond with the water quality sampling described in the next section. 
The Aero-Chem Metrics model 301 l] wet-dry precipitation collector (see figure 2) was chosen to collect samples because it is an easily maintained piece of equipment with a good history of operating for long periods of time in harsh climates. Precipitation consists of rainfall (wet fallout) and dry fallout that comes down when there is no water to accompany it. Normally, in the deserts of Saudi Arabia snow and ice do not need to be considered as part of the wet fallout.

The Aero-Chem Metrics precipitation collector consists of two plastic buckets, a moveable lid that can cover either bucket, a motor to move the cover, and a sensor to tell the cover when to move. (See figure 2) The motor is powered by a 12 volt wet cell automobile battery which is kept charged by a Solarex Corporation solar panel connected to the sampler.

1) The use of brand names in this report is for identification purposes only and does not constitute endorsement by the U.S. Geological Survey or the Ministry of Agriculture and Water (Saudi Arabia). 
The Aero-Chem sampler is designed to collect rain in a bucket which is open only during rainfall events. The second bucket is uncovered between rainfall events and only collects dry deposited material called dry fallout. The sensor detects the occurrence of rainfall and activates the motor which moves the cover from the wet collector to the dry collector. The cover and the arms supporting the cover are teflon coated to reduce corrosion and sample contamination.

The sensor consists of a stainless steel grid positioned above, but isolated from a stainless steel base plate. The sensing circuit is activated when water droplets bridge the gap between the elements and reduce the resistance. The sensor base plate is heated during the rainfall cycle to increase the rate of evaporation and reduce the exposure of the wet collector after rainfall ceases.

The sample collection buckets are formed from high density polyethylene plastic to reduce contamination of the sample. A lid with a tight "O" ring seal is provided to permit quantitative handling of the buckets. Both buckets are held in place by spring clips but are easily removed and exchanged for clean ones.

A polyurethane foam pad, enclosed in polyethylene film, is fastened to the underside of the cover to ensure a tight seal with the collection vessel. The seal reduces evaporation losses from the sample and prevents particulate matter to enter the wet collector during dry periods. Pressure on the pad is provided by spring tension in the cover arm. 
Dry fallout buckets were changed at approximately two month intervals and the dry material scrubbed down from the sides and bottom and dissolved in one liter distilled water for laboratory analysis. One liter of water is necessary for proper laboratory analysis.

Rainfall samples were collected by pouring the water from the wet bucket into a one liter polyethylene bottle after the collection of a rainfall event. The bottles were then sealed and sent to the laboratory for analysis. Since the amount collected was dependent upon the intensity of the storm, the amount for analysis was highly variable. For example, a storm of 0.2 millimeters was insufficient to cover the bottom of a one liter bottle. For this reason, it was sometimes possible to analyze the sample only for electrical conductance and $\mathrm{pH}$, and usually only for major ions.

Samplers were assembled at the site and fastened to the ground with heavy cinder blocks or iron rods driven into the ground. (See-figure 2) Field office personnel of the Ministry of Agriculture and Water assisted in the installation of the instruments and the collection of dry fallout and rainfall samples .

Laboratory analysis was provided by the water laboratory at the Ministry of Agriculture and Water's Regional Agriculture and Water Research Center in Riyadh. The assistance of the laboratory in obtaining the necessary parameters is greatly appreciated by the authors. 


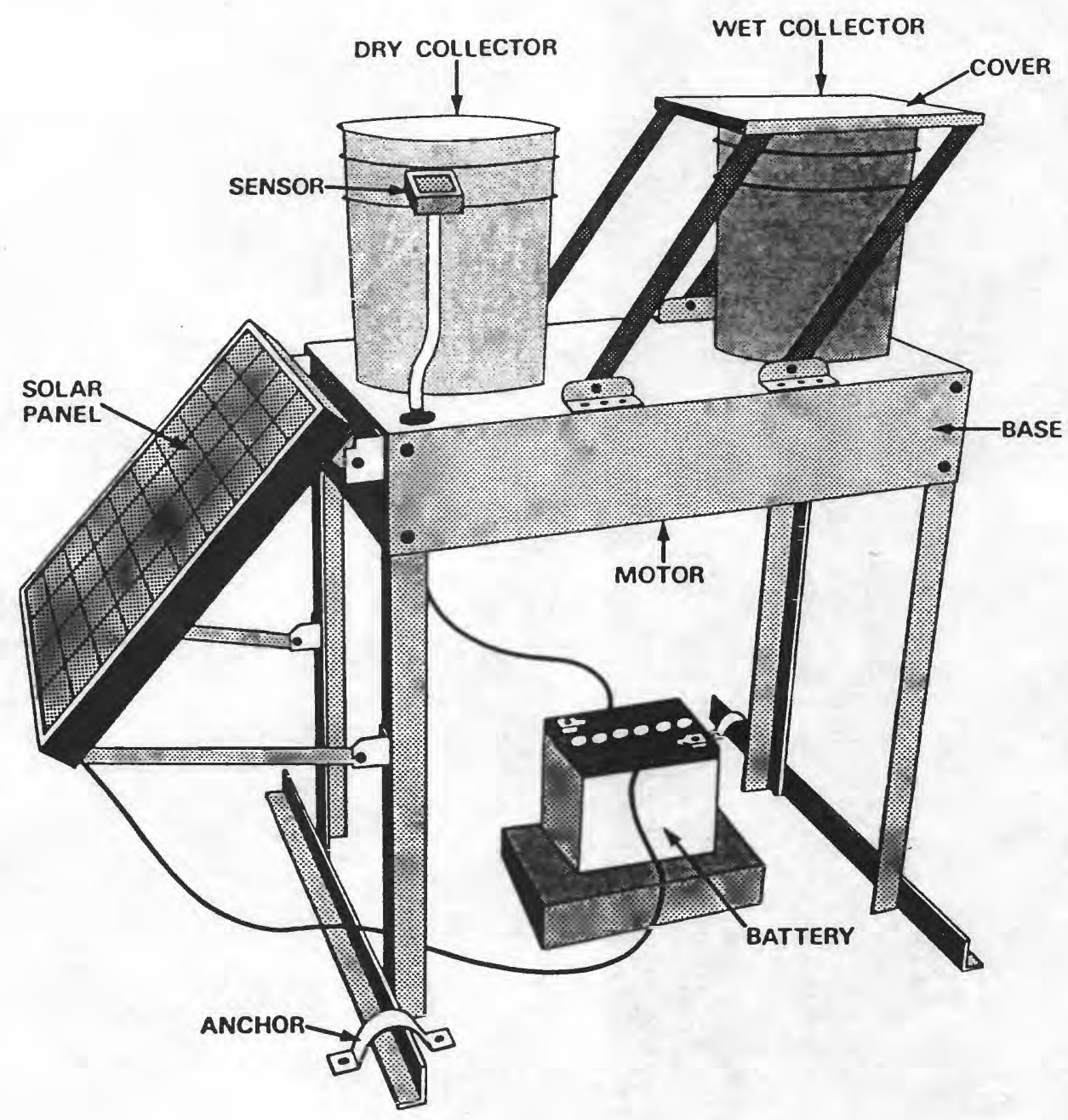

Figure 2.-- Sketch of Wet-Dry Precipitation Collector 
Rainfall Quality Samples

Since the installation of samplers in Apri1, 1983, rainfall has been below normal in Saudi Arabia. Only 16.9 millimeters of rainfall have been measured in Riyadh, 0.6 millimeters have been measured in Hufuf, and 2.0 millimeters have been measured in Tabuk during 1983. Even Abha has been slightly below average rainfall with 126.8 millimeters during the period. (See Table 1)

Eleven samples of precipitation have been collected from the sampler in Riyadh. The amount of rain in the storms varied from 0.2 millimeter to 17.7 millimeters so the samples varied from a trace to about 1100 milliliters. Four samples of rainfall have been collected from the sampler in Abha. The amount of rain in the storms varied from 5.4 millimeters to 12.6 millimeters so the samples exceeded 1000 milliliters in several cases. One sample of rain was collected in Tabuk from the sampler and the storm brought 2.0 millimeters or about 50 milliliters of water. At Hufuf only 0.6 millimeter of rain was recorded in 1983, and that occurred in May. 
Table 1 -- Rainfall Recorded During Study

Compared to 18 Year Average

Year Jan Feb Mar Apr May Jun Jul Aug Sep Oct Nov Dec Total Location $=$ Riyadh $($ R001)

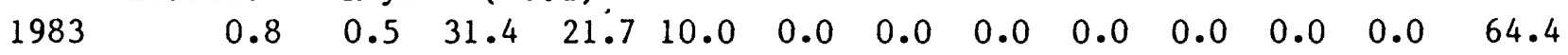

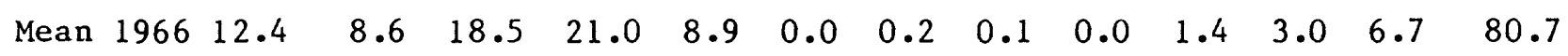
to 1983

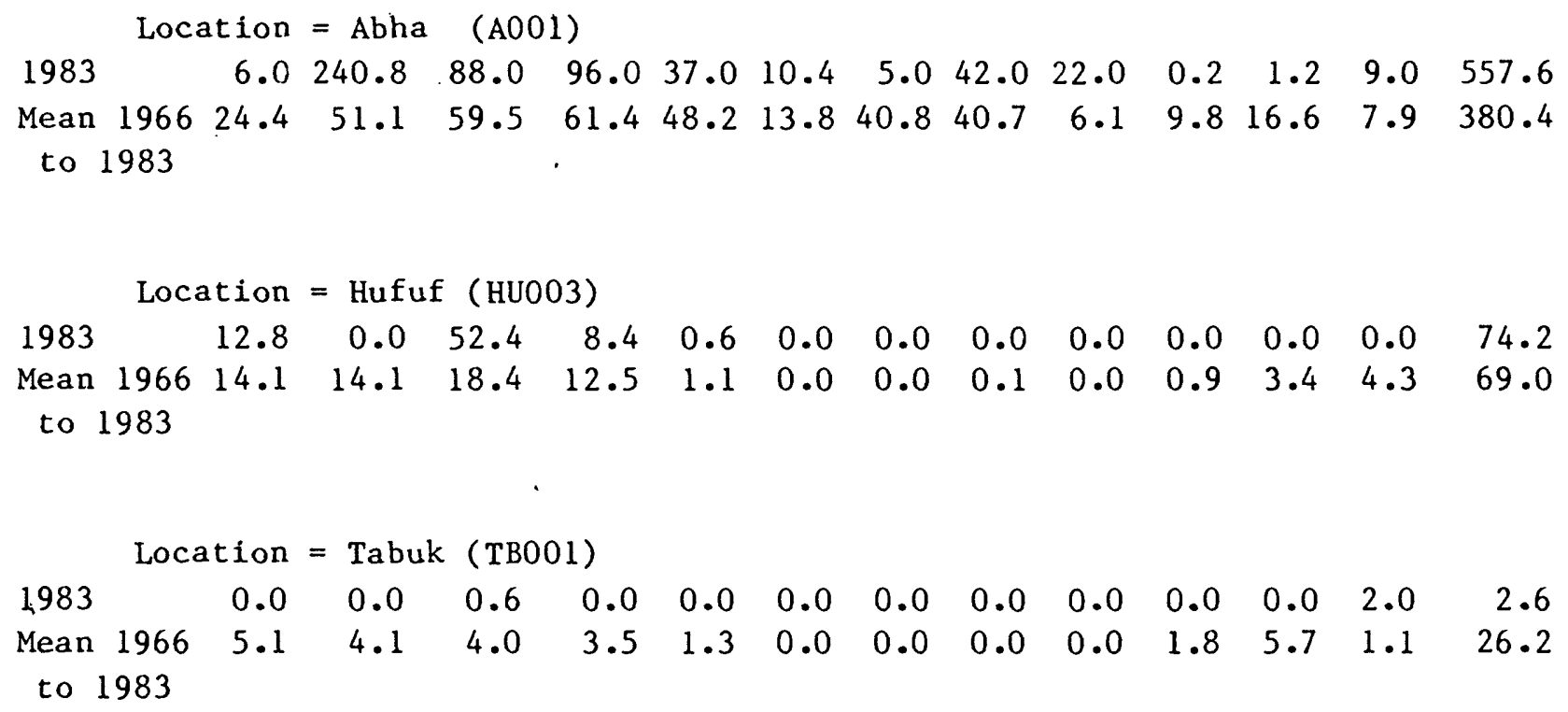


Electrical conductivity and $\mathrm{pH}$ were analyzed on each rainfall sample collected. If there were enough water the following parameters were determined in the order shown as priority: nitrate, sulfate, chloride, calcium, magnesium, sodium, potassium, bicarbonate-carbonate, fluoride, boron, total dissolved solids, and phosphate. Methodology was based on Standard Methods for the Examination of Water and Wastewater, 1980.

The eleven samples from Riyadh have a low electrical conductivity of 55 Ymhos and a high electrical conductivity of 310 个mhos. All eleven pH values are greater than or equal to 7.5 units indicating no acid rainfall effects presently occur. Calcium, bicarbonate, and sulfate are the major ions present. Due to the small amounts of water collected, data for sodium, potassium, and chloride are scarce although it can be postulated that there is some effect from the seawater of the Red Sea or Arabian Gulf at Riyadh. The small amounts of nitrate and the neutral $\mathrm{pH}$ measurements indicate sulfate probably comes from calcium and magnesium sulfates associated with small dust particles rather than from sulfuric acid or nitric acid as in the case of the low nitrates. (Herrman, 1983) Fluoride and boron are in very small concentrations. (See Table 2) 


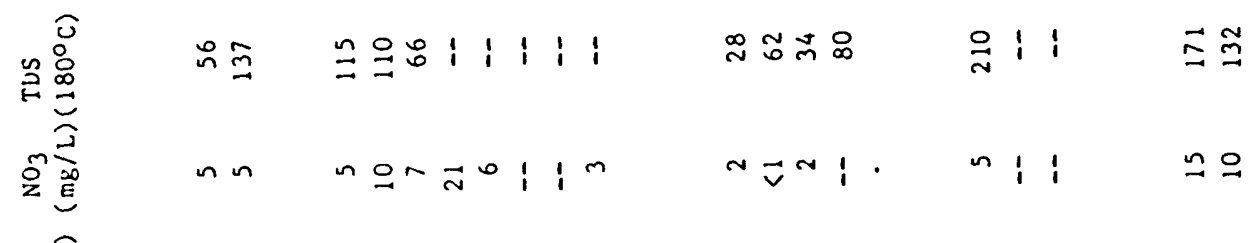

竞

- 疍

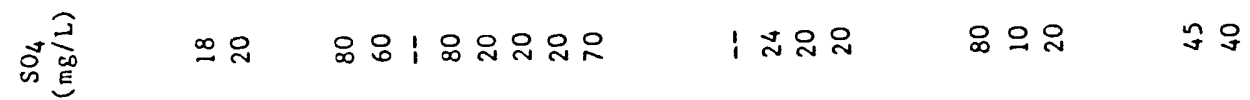

瑝

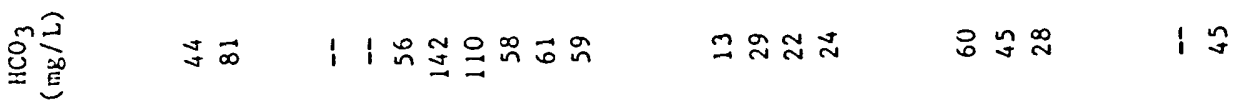

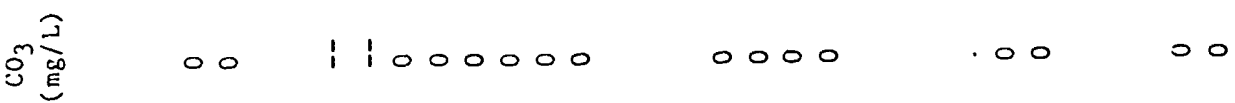

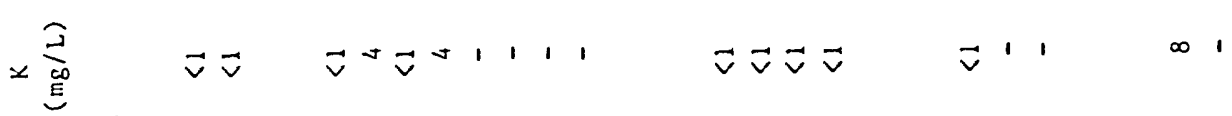

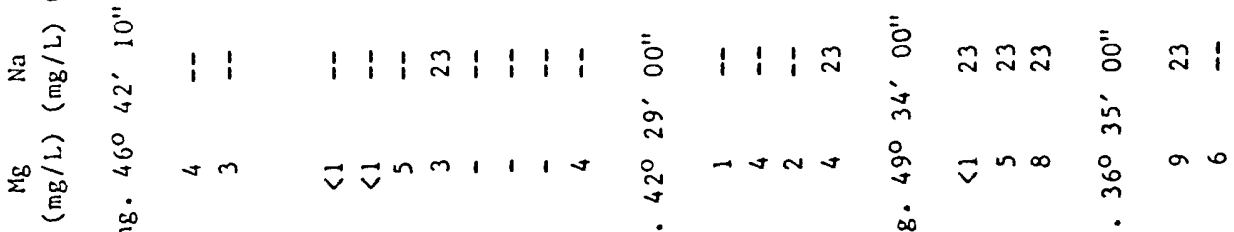

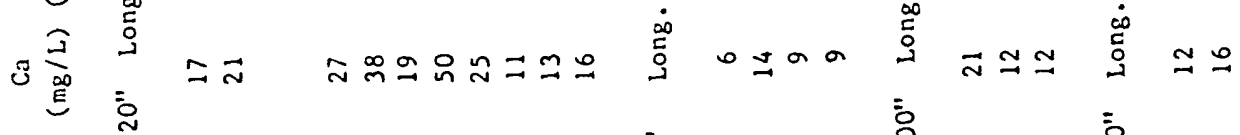

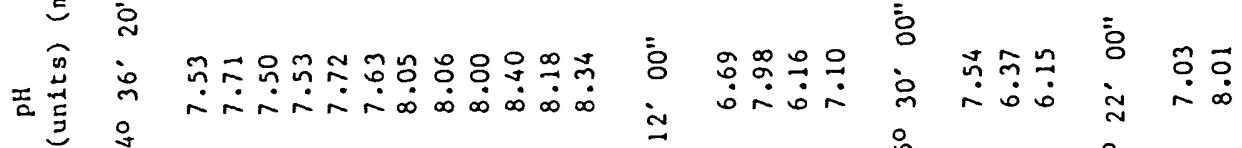

柁全

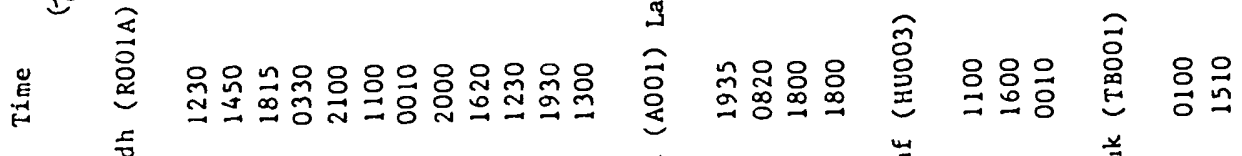

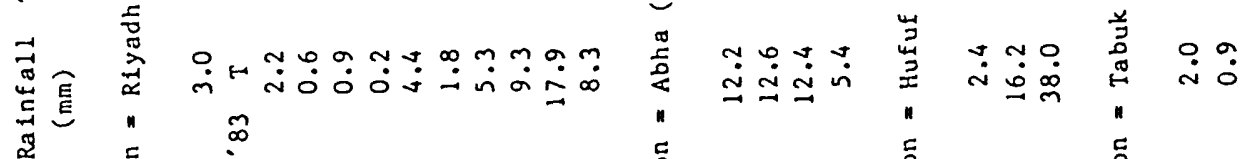

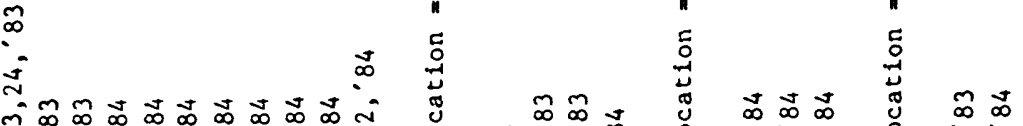

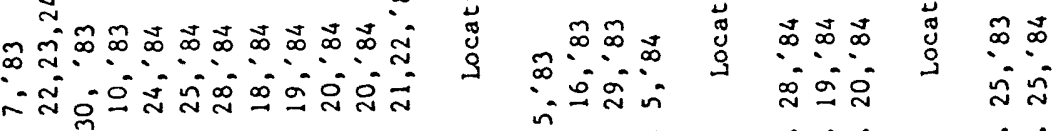

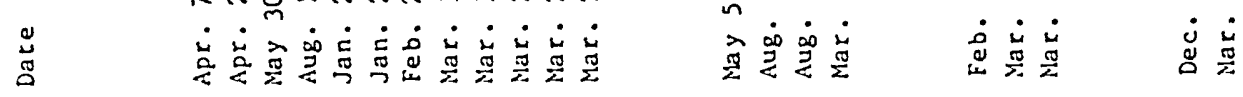


The four samples from Abha have a low electrical conductivity of 50 ymhos and a high electrical conductivity of 80 ?mhos. The $\mathrm{pH}$ values are more acidic than those measured at Riyadh, with values as low as 6.16 units, but still not in the ranges known as acid rain. Calcium and sulfate were found, probably associated with small concentrations of bicarbonate. No sodium, potassium, or chloride were determined even though one would expect considerable influence from seawater from the Red Sea. Small concentrations of nitrate and fluoride were found but not enough nitrate to postulate the presence of nitric acid. Some small amounts of sulfuric acid could be present as indicated by the lower $\mathrm{pH}$ and presence of sulfate. However, the sulfate could be associated with calcium and washed down as dust particles.

The single sample from Tabuk has the highest electrical conductivity of any of the rainfall samples, 270 tmhos. The $\mathrm{pH}$ was 7.03 or very near neutral. Sodium, calcium, and chloride were the dominant ions indicating the possibility of seawater droplets from the Red Sea or from the Mediterranean Sea being carried in by prevailing winds. Sulfate and nitrate were also present in significant amounts but the neutral pH probably indicates the source was dust particles and atmospheric conversion rather than from sulfuric or nitric acids. Small concentrations of magnesium, potassium, and fluoride were also found. 
The single sample from Hufuf has an electrical conductivity of 270 \}mhos, the same as the sample from Tabuk. The pH was 7.54 , slightly above neutral. Sodium, calcium, bicarbonate and sulfate were the dominant ions, with sulfate higher than any sample collected except the January 24, 1984 sample from Riyadh. Calcium, sulfate, and bicarbonate were probably contributed by dust particles and the low chloride indicated a lack of contribution from seawater aerosols. Some nitrate was present but the basic pH probably indicates little effect from nitric or sulfuric acids. This sample also contained the highest dissolved solids of any sample collected, probably due to the high sulfate. 


\section{Dry Fallout Samples}

Dry fallout samples have been tabulated in Table 3. The concentrations of individual parameters are expressed in milligrams per liter (mg/L.) because the dry material was dissolved in one liter distilled water. The dry material in the collector represents the larger sized particles of local origin that move relatively close to the ground. Collection of this material is not quantitative over the interval of collection and is known to vary widely even between closely spaced samplers. For this reason comparison of data in Table 3 was general and not rigorous in this report.

Dry fallout collectors were removed every two months and scrubbed down and sent to the laboratory. In Riyadh, two samples represent three months but generally, samples represent two months. Whether the two month period represents an accumulation of material or an equilibrium with material moving in and out for two months is currently open to question. Two months is also a compromise between having a large number of samples and a large amount of extra work in the field. When more is known about the collection of dry fallout, a frequency of one sample per month may be more useful for interpretation of the results. 


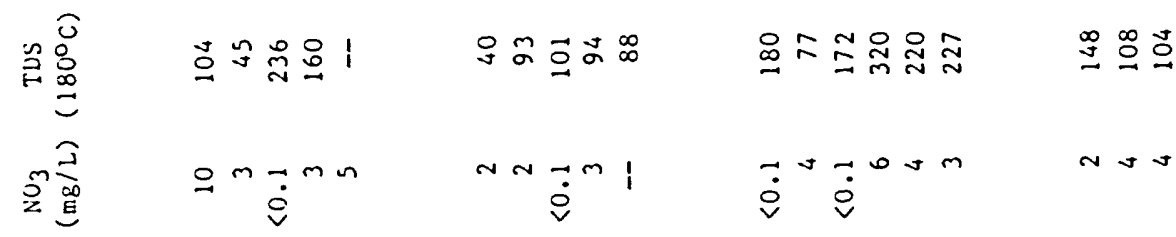

$\Rightarrow$ 疍

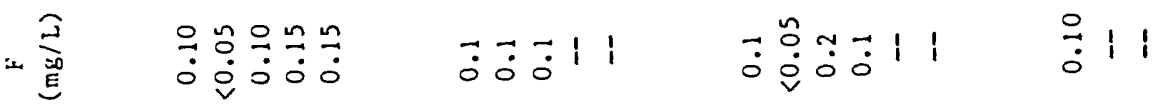

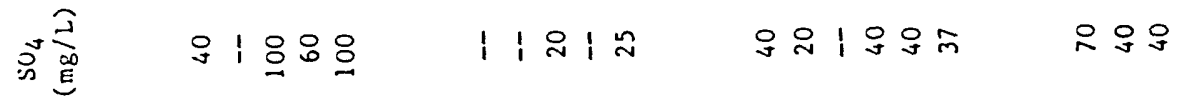

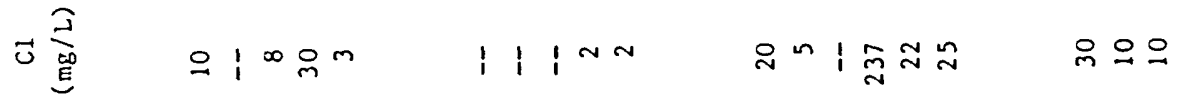

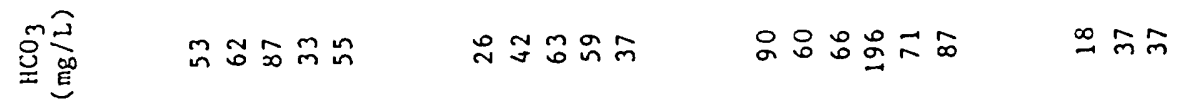

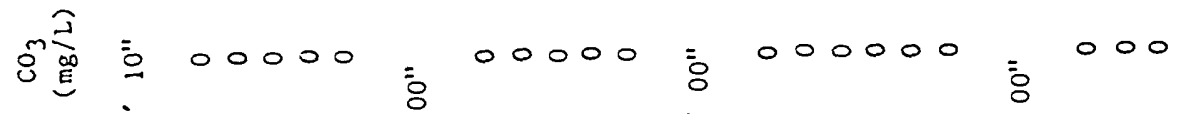
$\times$ 兽

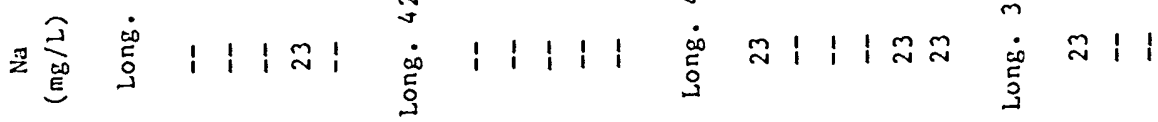

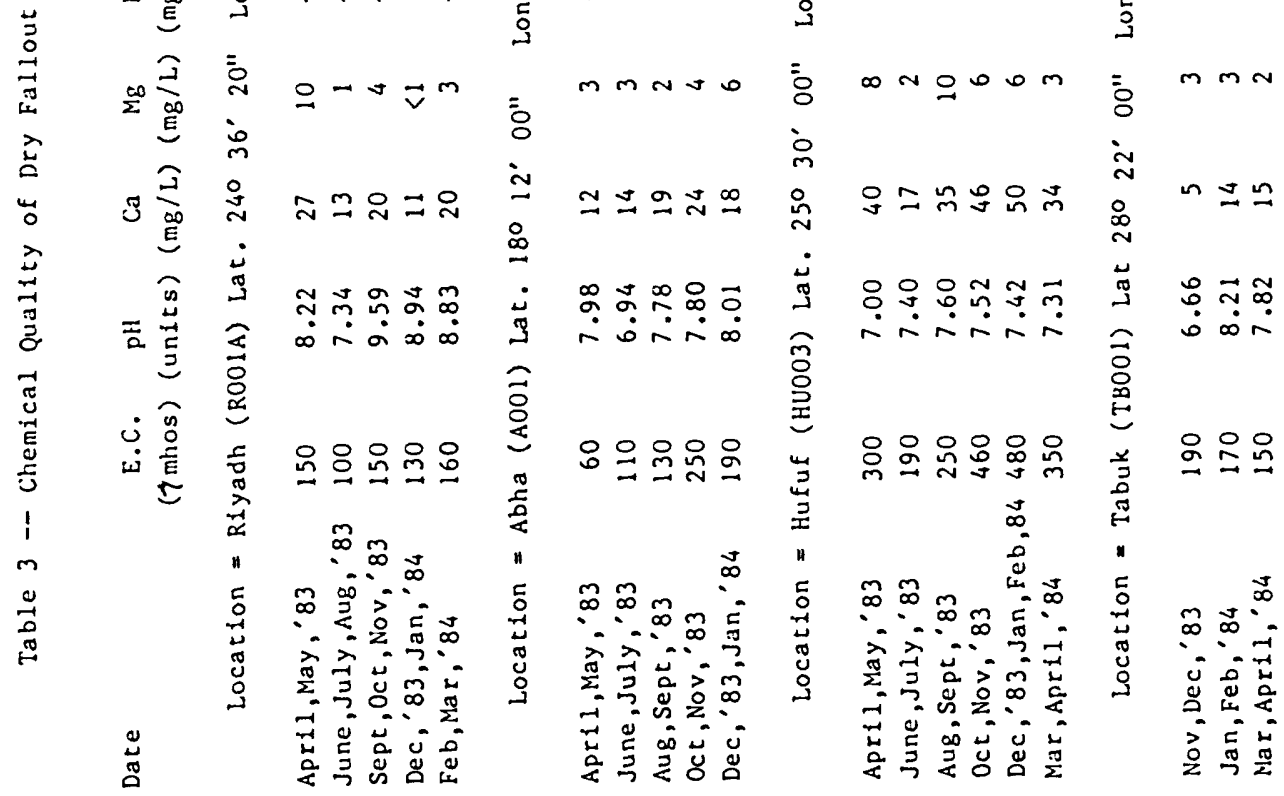


To be consistent with the analysis performed on the wet samples, electrical conductivity, pH, calcium, magnesium, sodium, potassium, bicarbonate-carbonate, chloride, sulfate, fluoride, boron, nitrate, total dissolved solids, and phosphate were determined on the dry fallout samples using the same methodology. (APHA, 1980)

In Riyadh, the dry fallout contained a predominance of calcium, bicarbonate, and sulfate ions similar to the wet fallout. The pH was also higher than neutral, but more variable. Small amounts of chloride were present but sodium and potassium were not determined on most of the samples. Concentrations of fluoride, boron, and nitrate were low.

Abha dry fallout was low in the concentration of calcium and bicarbonate ions. Only one sample had sulfate and no sodium or chloride were determined. However, two samples have low concentrations of potassium. Small concentrations of fluoride and nitrate were present, and the $\mathrm{pH}$ was neutral or slightly more basic.

In Hufuf, calcium and bicarbonate dominate with lesser amounts of chloride and sulfate, except in the October-November sample where sulfate was high. One sample contained sodium and two other samples contained low concentrations of potassium. Fluoride, boron, and nitrate were all present in low concentrations, and the $\mathrm{pH}$ was near neutral. 
The single sample from Tabuk is predominantly sodium sulfate with lesser amounts of calcium, bicarbonate, and chloride. Fluoride and nitrate were also present in small amounts.

The samples from Hufuf are more concentrated and nearer neutral $\mathrm{pH}$ than the samples from Riyadh, Tabuk, and Abha. Samples from Riyadh have the highest $\mathrm{pH}^{\prime} \mathrm{s}$ and nitrates. Samples from Abha are the least concentrated and contain the least amount of dissolved ions. Samples from all sites contained calcium, bicarbonate and lesser amounts of other ions, except for one sample from Hufuf with high chloride and the sample from Tabuk with high sulfate concentrations. All samples were similar in concentration to the wet samples taken concurrently. 


\section{SUMMARY AND CONCLUSIONS}

Information collected for this report indicated that several years of data will be needed to adequately describe variations in rainfall in Saudi Arabia. This is due to the lack of rainfall in this desert climate and the long periods of time between storms. As additional samples are collected, and more detailed data becomes available, more specific conclusions may be drawn.

Expansion of the sampling network from four to eight stations will provide data on additional areas and possibly allow the study of trace metals and isotope ratios. New sites are proposed for Buraydah, Sulayyil, Jeddah, and Jubail.

Even though rainfall has been scant, data indicate that the $\mathrm{pH}$ of rainfall in Saudi Arabia is near neutral or basic, indicating a lack of effect from imported nitric or sulfuric acids. Sodium and chloride from the Red Sea or the Arabian Gulf do not appear to be present in the rainfall in appreciable amounts. Particles of calcium, bicarbonate, or sulfate from local disturbances appear to be more important to the chemical quality of rainfall than ions from greater distances. Dry fallout is similar in concentration to the rainfall samples collected concurrently. 


\section{REFERENCES}

APHA, 1980: Standard Methods for the Examination of Water and Wastewater, $15 \mathrm{t}$ ed.

Al-Qurashi, M.D.A., 1981, Synoptic Climatology of the Rainfall in the Southwest Region of Saudi Arabia: Master's of Science Thesis, Western Michigan University, Kalamazoo, Michigan.

El Khatib, A.B., 1980, Seven Green Spikes: Water and Agricultural Development, 2d ed., Ministry of Agriculture and Water, Saudi Arabia.

Herrman, R., and Johnson, A. I., 1983, Acid Rain, A Water Resources Issue for the 80's: American Water Resources Association.

Ministry of Agriculture and Water, 1981, Monthly Hydrologic Data for 1966-70: v. 1, Rainfa11 no. 95, Ministry of Agriculture and Water, Saudi Arabia.

Ministry of Agriculture and Water, 1982, Monthly Hydrologic Data for 1971-75: v. 1, Rainfall no. 97, Ministry of Agriculture and Water, Saudi Arabia.

Ministry of Agriculture and Water, 1982, Monthly Hydrologic Data for 1976-80: v. 1, Rainfall no. 98, Ministry of Agriculture and Water, Saudi Arabia.

Ministry of Agriculture and Water, 1983, Monthly Climate Data for the year 1981: Hydrology Publication no. 99, Ministry of Agriculture and Water, Saudi Arabia.

Moore, D. O., et. a1 (In Press), Water Atlas of of Saudi Arabia: Ministry of Agriculture and Water, Water Resources Development Department.

Schyfsma, E., 1978, in Al-Sayari, S.S., and Zotl, J.G., eds., Quaternary Period in Saudi Arabia: Wien-New York, Springer-Verlag.

Shampine, W.J., Dincer, T., Noory, M., 1979, in Isotope Hydrology, 1978, An Evaluation of Isotope Concentrations in the Ground Water of Saudi Arabia: International Atomic Energy Agency, Vienna, Austria.

Williams, R.0., 1979, Meteorological and Oceanographic Data for the Eastern Province Region of Saudi Arabia: Aramco, Dhahran, Saudi Arabia. 